Editorial

\title{
Introduction: Migration and Unequal Positions in a Transnational Perspective
}

\author{
Thomas Faist ${ }^{1}$, Joanna J. Fröhlich ${ }^{1}$, Inka Stock ${ }^{1}$ and Ingrid Tucci ${ }^{2}$ \\ ${ }^{1}$ Centre on Migration, Citizenship and Development, Department of Sociology, Bielefeld University, 33615 Bielefeld, \\ Germany; E-Mails: thomas.faist@uni-bielefeld.de (T.F.), joanna.froehlich@uni-bielefeld.de (J.F.), \\ inka.stock@uni-bielefeld.de (I.S.) \\ ${ }^{2}$ LEST-Institute for Labour Economics and Industrial Sociology, CNRS, Aix Marseille University, 13326 Aix-en-Provence, \\ France; E-Mail: ingrid.tucci@univ-amu.fr \\ * Corresponding author
}

Submitted: 20 January 2021 | Published: 18 February 2021

\begin{abstract}
How does spatial mobility influence social mobility and vice versa? Often, the 'objective' structural positions on the one hand, and the 'subjective' definition of social positions on the other hand, are not considered together. Yet this is necessary in order to gauge the consequences of mobility trajectories reaching across borders. This framing editorial asks how we can study the interplay of perceptions of one's own social position and one's objective social position to better understand how spatial mobility influences social mobility and vice versa. In short, this means an exploration of the nexus of spatial mobility and social mobility. Exploring that nexus requires attention to objective social positions, subjective social positioning strategies, transnational approaches to the study of social positions and self-positioning, and social boundary theory. Overall, the complexity of the nexus between social and spatial mobilities calls for a multifaceted research approach that covers various levels of analysis. Some of the contributions feature a mixed-methods approach that allows drawing a multifaceted picture of the interrelation between the perceptions of social positions and their structural features.
\end{abstract}

\section{Keywords}

migration; social inequalities; social mobility; social positioning; social positions; transnational social spaces

\section{Issue}

This editorial is part of the issue "Migration and Unequal Social Positions in a Transnational Perspective" edited by Thomas Faist (Bielefeld University, Germany).

(C) 2021 by the authors; licensee Cogitatio (Lisbon, Portugal). This article is licensed under a Creative Commons Attribution 4.0 International License (CC BY).

\section{Focusing on the Nexus between Social and Spatial Mobility: Ways to Conceptualise Social Inequality in Transnational Spaces}

Who gains from migration and who loses socially? How does geographical mobility affect social class and status? These questions concern how inequalities are negotiated and reproduced in transnational spaces and across nation states (Faist, 2019). However, investigating empirically the nexus between social and spatial mobility is a complex task, and there have been few comprehensive attempts thus far (Faist, 2016). In the European con- text, for example, research has found that spatial mobility across borders indeed goes along with differences in people's life chances compared to the non-mobile population (Verwiebe, Wiesböck, \& Teitzer, 2014). Scholars also find that the experiences of migrants are to a great extent unequal due to differences in people's country of emigration, their education credentials, occupational skills, and legal and citizenship status (Faist, 2014; Martin, 2009; Nohl, Schittenhelm, \& Weiss, 2014). Mobility can be considered as "an element of social differentiation" (Moret, 2017, p. 2). The associated patterns of spatial mobility are diverse. Some leave their country of origin 
and settle directly in another country, while others have multiple experiences of migration as well as settlement in several countries. Again, this diversity in migration patterns may make a difference not only for social positions but also social positioning. Contributing to such differentiation in stratification are, among others, processes of racialization and gender, which influence migrants' social positions and their evaluations in both origin and destination countries (Erel \& Reynolds, 2017).

Transnational practices and their interrelation with social inequality are at the core of various studies (Favell \& Recchi, 2011; Mau \& Mewes, 2012; Recchi et al., 2019). By combining perspectives on social positions and social positioning, the research presented in this issue yields important insights into the processes whereby social inequality is linked to the creation of (trans-)national social spaces. While there has been ground-breaking research describing how structural inequalities are (re-)produced (e.g., Schneider \& Collet, 2010), much less investigation has been made of mobile people's own evaluations of their social positions in interplay with (trans-)national social structures. In particular, there is only limited empirical work on the interplay of both the socioeconomic and political conditions that frame social and geographical mobility across spaces, and the subjective sense-making processes that people engage in in order to position themselves socially. Knowledge about the interrelation of migrants' own perspectives on social class and status and social mobility in and across different locations, and the structural factors that shape inequality across national borders, could contribute to a better understanding of migrants' mobility strategies, their plans for social mobility, and their potential success. Such an endeavour enhances our knowledge of how mobility shapes lives and life choices, and how mobility affects the reproduction of social inequalities across national and local spaces. Here, mobility refers, in a very general sense, to movement in geographical space and captures patterns of both daily and more exceptional movement. Migration is used here to denote a more specific kind of mobility across the borders of national states.

\section{Social Positions, Social Positionings, and Social Class}

Attention is given in this issue to the largely unmentioned potential ambiguity between two facets of social positions: a person's socio-economic position and the perception and evaluation of that person's socio-economic position. Social position is, in general, understood as a person's place within a given social hierarchy and the tasks and prestige attached to that particular place. To analyse the diverse trajectories of migration in relation to individuals' social positions, as well as the way in which mobile persons interpret these positions, both 'objective' and 'subjective' social positions of mobile persons need to be considered. 'Objective' social position refers to someone's social position within a cer- tain pattern of social stratification viz. social hierarchy, as measured by standardized indicators (e.g., the EGP scheme by Erikson, Goldthorpe, \& Portocarero, 1979). The 'subjective' dimension of social positions-social positioning-relates to evaluations and interpretations derived from the individual's points of view.

How an individual evaluates his or her own position and the associated changes in that position over time may not match the position assigned to that person based on standardized socioeconomic indicators. It is important to consider both dimensions of social positions, because the objectively determined positions can indicate only the social hierarchy, not how people position themselves within it (Lindemann \& Saar, 2014).

Social hierarchies are usually understood to exist within nation states. Transnational scholarship, however, emphasizes that the links between people and flows of goods and ideas lead to the emergence of transnational social spaces (or transnational social fields) characterized by the transformation of borders, social relations, and heterogeneities. Therefore, migrants often occupy social positions in the regions of both origin and destination simultaneously (Nowicka, 2013; Suárez-Orozco \& Suárez-Orozco, 1995), which can lead to status paradoxes in transnational social spaces (Erel \& Ryan, 2018; Nieswand, 2011). Having simultaneous locations in transnational social spaces suggests that evaluations of social positions are framed not only by the immigration country but also by experiences in the emigration country and eventually the transnational social space as such. Thus, the contributions approach the issue of spatial mobility and social position(ing) within transnational spaces with distinct social hierarchies within which people are positioned according to different heterogeneities, such as the degree of mobility, transnationality, ethnicity, gender, and class. In accounting for how migration, together with other heterogeneities, produces unequal social positions, the articles provide valuable insights into the social stratification and the inequalities in life chances of various populations.

In processes of social stratification, various heterogeneities play a role. It is important to point out that the contributions to this issue do not give priority to certain differences viz. heterogeneities between individuals and groups, such as class. Here, class is treated as social class in the Weberian sense, as opportunities and positions associated with market processes (Weber, 1922/1968). It is thus a marker of difference along with others, such as gender, ethnicity, race, or religion. The articles in this issue also explicitly take into account patterns of migration and the degree of transnationality as heterogeneities to be considered because previous research has established that the degree of cross-border interconnectedness does play a role in the (re)production of social inequalities (Faist, Bilecen, Barglowski, \& Sienkiewicz, 2015). 


\section{Operationalising the Study of the Nexus between Social Status and Mobility: Boundaries, Social Comparison, and Capabilities}

Two concepts are important in approaching the theoretical and empirical analyses presented in this issue: boundary making and social comparison. The articles in this issue all use in different ways a transnational perspective and a boundary-making approach and/or social comparisons that allow the use of both actor-centred views on social position and structural perspectives on social inequalities (e.g., Lamont, 1992). The article by Eichsteller (2021) introduces, in addition, Sen's capability approach in suggesting ways in which the analysis of the nexus between social stratification and geographical mobility could take place.

The practices of symbolic boundary making (Lamont \& Molnár, 2002, based on Barth, 1969) are important objects of analysis here because they allow accounting for the creation of boundaries that justify the inclusion and exclusion of migrants in society-for example, on the basis of ethnic origins or migration status. Most specifically, Lamont and Molnár (2002, p. 3) defined symbolic boundaries as the differences that people themselves draw in order to categorise and situate themselves and other people, things, and practices within social hierarchies. Lamont (1992) distinguishes three different groups of symbolic boundaries: socioeconomic boundaries, cultural boundaries, and moral boundaries. These boundary-making processes are dynamic and dependent on the power relations and interests of different groups in society. In particular, Stock and Fröhlich (2021) and Stock (2021) use boundary theory in order to analyse how migrants make sense of their social standing visà-vis others in society. Implicitly, the ways in which migrants deal with outside evaluations of their economic, social, or cultural positions are also dealt with in the articles by Salamońska and Winiarska (2021), Lévy and Li (2021) and Waldendorf (2021). They all show that subjective status evaluations often do not mirror outside ascriptions, but rather incorporate very personal and subjective aspects which help to portray the responding migrants' subjective positions in a positive light compared to others. Boundary theory appears thus to present interesting avenues for exploring this interplay between objectively ascribed and subjectively experienced social positions.

In order to establish their position in relation to others, mobile people and their immobile significant others may also recur to the practices of social comparison (see Sienkiewicz, Hapke, \& Faist, 2016). Earlier research found, for example, that cross-national comparisons frame the experience of social inequalities, such as relative (dis-)advantage, which can lead to situations of losing face, of conflict, and of frustration within families and beyond (Faist et al., 2015). The relevance of such comparisons to social interactions and to evaluations of justice, fairness, and (in-)equality is key (see the classic studies by, e.g., Blau, 1964). Although Panning (1983, p. 329) mentioned the crucial role of "political, cultural, geographic, and institutional" heterogeneity in the development of frames for comparisons as long ago as the early 1980s, attempts to empirically investigate how such heterogeneities correspond with the way social comparisons are deployed have been fairly recent. For instance, recent studies have shown that differences in class (Sachweh, 2013) and in gender (Kruphölter, Sauer, \& Valet, 2015) are factors that people take into consideration when comparing and evaluating equality and justice. Research has also revealed that migrants create "transnational spaces of comparison" (Sienkiewicz, Sadovskaya, \& Amelina, 2015, p. 280, in which, for example, informal social protection is evaluated and distributed differently in the national context, meaning that the receiver of formal protection in a national frame may be the provider of informal protection in a transnational frame. However, the ways in which these frames of comparisons are shaped by migration are yet to be investigated. Thus, there is a need to determine the criteria upon which the selection of comparisons differs among different types of mobile persons by considering that frames of reference may be directed toward different countries. Stock (2021), for example, shows how comparisons are context dependent and directed at varying types of people, within and across borders, which, in turn, leads people to evaluate their own social position as either better or worse than the social position of those with whom they compare themselves. Salamońska and Winiarska (2021) contribute to this discussion by analysing the multiple frames of reference that Polish migrants use in order to make sense of their social standing after various migratory spells in different settings.

Eichsteller (2021) contributes a potentially useful third conceptual tool to investigate the nexus between transnational inequalities and migration. She builds on Amartya Sen's capability approach to conceptualise migrants' embeddedness in the framework of social inequalities and explores the relationship between individual choices, resources, and entitlements. The author suggests that Sen's conceptual approach provides innovative insights into migration experiences and opens up new avenues for the discussion of migrants' social justice.

The three conceptual approaches that are discussed in this thematic issue thus point to some of the innovative ways in which migration scholars could engage with the literatures in such diverse fields as social psychology (social comparison), cultural sociology (boundary making), and economics (capability approach) to find new ways to engage with the intellectual puzzles that the nexus between social inequality and migration are representing.

\section{Methodological Challenges in the Study of the Nexus between Migration and Social Inequality}

One of the methodological difficulties of using both social comparisons and symbolic boundary approaches 
to explore the nexus between migration and social inequality relates surely to the complexity of analysing the interplay of multiple processes of comparisons and boundary-drawing that people engage in. This challenge needs to be confronted by adapting and combining available research methods and methodologies.

Ultimately, research needs to draw on both quantitative and qualitative methodology to gain a better understanding of social positions and social positioning, and the relation between these two dimensions. Accordingly, this issue features several articles addressing boundaries and social comparisons with mixed-methods to contribute new and valuable insights for the understanding of social positions and positioning (Salamońska \& Winiarska, 2021; Söhn \& Prekodravac, 2021; Stock \& Fröhlich, 2021). Beyond that, innovative ways to challenge methodological nationalism (Faist, 2012) and to go beyond mono-dimensional heterogeneities, such as ethnicity (and ethicising) are presented in this issue. Tucci, Fröhlich, and Stock (2021) employ a mixed-methods approach, based on data-driven grouping of migrants, migration trajectories, and cultural capital. Such an approach helps to study and understand symbolic boundaries in a multifaceted way. In these ways, this issue contributes to establishing the study of social positions and social positionings as a promising venue for further research.

\section{Acknowledgments}

Great thanks go to the anonymous reviewers for their helpful comments on all the articles in this thematic issue. Thanks also to the participants in the final workshop of the project "Transnational Mobility and Social Positions in the European Union" (TRANSMOB) for their insightful suggestions on the overall project results: Adrian Favell, Janina Söhn, Justyna Salamońska, Karolina Barglowski, Maja Cederberg, Martha Eichsteller, Patrick Sachweh, Tabea Scharrer, and Umut Erel. The research presented in four of these articles (Stock, 2021; Stock \& Fröhlich, 2021; Tucci, Fröhlich, \& Stock, 2021; Waldendorf, 2021) would not have been possible without the generous financial support of the German Research Foundation (DFG) for the TRANSMOB project (FA 284/10-1; PI: Thomas Faist; post-doctoral researchers: Inka Stock and Joanna Jadwiga Fröhlich). Research in the frames of the TRANSMOB project would not have been possible without the great support of the German Institute for Economic Research (DIW) as well as KANTAR public, who are conducting the SOEP survey. Support for the project also came from Nicolas Legewie (DIW) and Andrea Gensicke (KANTAR Public). Special thanks go to Ingrid Tucci for fruitful cooperation, and to the student assistants Anica Waldendorf, Isabell Diekmann, Joana Heuser, Maximilian Wächter, and Victoria Volmer for their help. Last but not least, thanks go to all SOEP participants for sharing the information about their life circumstances and particularly to the more than 30 participants to who agreed to open their houses to researchers from the TRANSMOB project and to share their life stories.

\section{Conflict of Interests}

The authors declare no conflict of interests.

\section{References}

Barth, F. (1969). Ethnic groups and boundaries: The social organization of culture difference. Boston, MA: Little, Brown.

Blau, P. M. (1964). Exchange and power in social life. London: Wiley \& Sons.

Eichsteller, M. (2021). Migration as a capability: Discussing Sen's capability approach in the context of international migration. Social Inclusion, 9(1), 174-181.

Erel, U., \& Reynolds, T. (2017). Introduction: Migrant mothers challenging racialized citizenship. Ethnic and Racial Studies, 41(1), 1-16.

Erel, U., \& Ryan, L. (2018). Migrant capitals: Proposing a multi-level spatio-temporal analytical framework. Sociology, 51(1). https://doi.org/10.1177\% 2F0038038518785298

Erikson, R., Goldthorpe, J. H., \& Portocarero, L. (1979). Intergenerational class mobility in three Western European societies: England, France and Sweden. The British Journal of Sociology, 30(4), 415-441.

Faist, T. (2012). Toward a transnational methodology: Methods to address methodological nationalism, essentialism, and positionality. Revue Européenne des Migrations Internationales, 28(1), 51-70.

Faist, T. (2014). On the transnational social question: How social inequalities are reproduced in Europe. Journal of European Social Policy, 24(3), 207-222.

Faist, T. (2016). Cross-border migration and social inequalities. Annual Review of Sociology, 42(1), 323-346.

Faist, T. (2019). The transnationalized social question: Migration and the politics of social inequalities in the twenty-first century. Oxford: Oxford University Press.

Faist, T., Bilecen, B., Barglowski, K., \& Sienkiewicz, J. (2015). Safety nets of migrants across borders: An inquiry into social mechanisms of inequality [Special Issue]. Population, Space and Place, 21(3). https:// doi.org/10.1002/psp.1884

Favell, A., \& Recchi, E. (2011). Social mobility and spatial mobility. In A. Favell \& V. Guiraudon (Eds.), Sociology of the European Union (pp. 50-75). Houndsmills: Palgrave Macmillan.

Kruphölter, S., Sauer, C., \& Valet, P. (2015). Occupational gender segregation and gender differences in justice evaluations (SFB 882 Working Paper Series No. 45). Bielefeld: DFG Research Center (SFB). Retrieved from https://pub.uni-bielefeld.de/record/2716937

Lamont, M. (1992). Money, morals, and manners: The 
culture of the French and the American upper-middle class. Chicago, IL: University of Chicago Press.

Lamont, M., \& Molnár, V. (2002). The study of boundaries in the social sciences. Annual Review of Sociology, 28(1), 167-195.

Lévy, F., \& Li, Y. (2021). Move abroad to move forward? Self-assessments of Chinese students and undocumented migrants in France. Social Inclusion, 9(1), 163-173.

Lindemann, K., \& Saar, E. (2014). Contextual effects on subjective position: Evidence from European countries. International Journal of Comparative Sociology, 55(1), 3-23.

Martin, P. (2009). The geography of inequalities in Europe. In G. Kochendörfer-Lucius \& B. Pleskovic (Eds.), Spatial disparities and development policy (pp. 239-56). Washington, DC: World Bank.

Mau, S., \& Mewes, J. (2012). Horizontal Europeanisation in contextual perspective: What drives cross-border activities within the European Union? European Societies, 14(1), 7-34.

Moret, J. (2017). Mobility capital: Somali migrants' trajectories of $(\mathrm{im})$ mobilities and the negotiation of social inequalities across borders. Geoforum, 116, 235-242.

Nieswand, B. (2011). Theorising transnational migration: The status paradox of migration. New York, NY: Routledge.

Nohl, A.-M., Schittenhelm, K., \& Weiss, A. (2014). Work in transition: Cultural capital and highly skilled migrants' passages into the labor market. Toronto: University of Toronto Press.

Nowicka, M. (2013). Positioning strategies of Polish entrepreneurs in Germany: Transnationalizing Bourdieu's notion of capital. International Sociology, 28(1), 29-47.

Panning, W. H. (1983). Inequality, social comparison, and relative deprivation. The American Political Science Review, 77(2), 323-329.

Recchi, E., Favell, A., Apaydin, F., Barbulescu, R., Braun, M., Ciornei, I., .. . Varela, A. (2019). Everyday Europe: Social transnationalism in an unsettled continent. Bristol: Policy Press.

Sachweh, P. (2013). Symbolische Grenzziehungen und subjektorientierte Sozialstrukturanalyse: Eine empirische Untersuchung aus einer Mixed-MethodsPerspektive [Symbolic boundaries and subjective approaches to stratification: An empirical investiga- tion from a mixed-methods perspective]. Zeitschrift für Soziologie, 42(1), 7-27.

Salamońska, J., \& Winiarska, A. (2021). New horizons? Comparisons and frames of reference of Polish multiple migrants worldwide. Social Inclusion, 9(1), 152-162.

Schneider, N. F., \& Collet, B. (Eds.). (2010). Mobile living across Europe II: Causes and consequences of job-related mobility in cross cultural comparison. Opladen: Barbara Budrich

Sienkiewicz, J. J., Hapke, P., \& Faist, T. (2016). Social comparisons in migration and inequality studies: $A$ literature review and evidence from a pilot study (SFB 882 Working Paper Series, 55). Bielefeld: DFG Research Center (SFB). Retrieved from https://pub. uni-bielefeld.de/download/2900936/2900937

Sienkiewicz, J. J., Sadovskaya, Y., \& Amelina, A. (2015). The Kazakh-German social space: Decreasing transnational ties and symbolic social protection. Population, Space and Place, 21(3), 270-281.

Söhn, J., \& Prekodravac, M. (2021). Upward, lateral, or downward? Multiple perspectives on migrants' educational mobilities. Social Inclusion, 9(1), 140-151.

Stock, I. (2021). Insights into the use of social comparison in migrants' transnational social positioning strategies. Social Inclusion, 9(1), 104-113.

Stock, I., \& Fröhlich, J. J. (2021). Migrants' social positioning strategies in transnational social spaces. Social Inclusion, 9(1), 91-103.

Suárez-Orozco, C., \& Suárez-Orozco, M. M. (1995). Transformations: Immigration, family life, and achievement motivation among Latino adolescents. Palo Alto, CA: Stanford University Press.

Tucci, I., Fröhlich, J. J., \& Stock, I. (2021) Exploring the nexus between migration and social positions using a mixed methods approach. Social Inclusion, 9(1), 114-129.

Verwiebe, R., Wiesböck, L., \& Teitzer, R. (2014). New forms of intra-European migration, labour market dynamics and social inequality in Europe. Migration Letters, 11(2), 125-136.

Waldendorf, A. (2021). Bridging the gap: Making sense of the disaccord between migrants' education and occupation. Social Inclusion, 9(1), 130-139.

Weber, M. (1968). Economy and society: An outline of interpretive sociology. Berkeley, CA: University of California Press. (Original work published 1922)

\section{About the Authors}

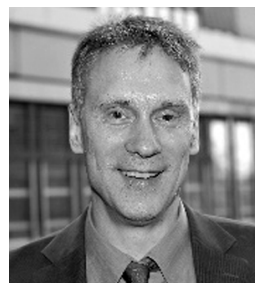

Thomas Faist is Professor of Sociology at Bielefeld University and a Member of the North RhineWestphalian Academy of Sciences and the Arts. His current work is concerned with the socio-ecological question (https://doi.org/10.1111/imig.12793). 


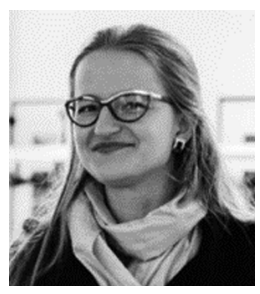

Joanna J. Fröhlich (née Sienkiewicz; dr. phil.) is Researcher in a project on "Transnational Mobility and Social Positions in the European Union" funded by the German Research Foundation (DFG) at Bielefeld University. In her doctoral thesis she studied the social protection networks of migrants from Kazakhstan in Germany and their relatives in Kazakhstan (2017). Her research interests include migration, social inequality and (transnational) research methods.

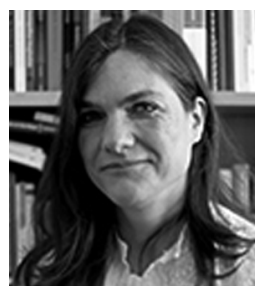

Inka Stock is a Postdoctoral Researcher at COMCAD at the Faculty of Sociology, Bielefeld University, Germany. She has a particular interest in the nexus between migration and inequality, migration and development, and gender and migration.

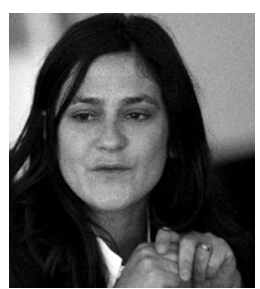

Ingrid Tucci is a Sociologist and a CNRS researcher at the Institute for Labour Economics and Industrial Sociology (LEST) at Aix Marseille University. She is interested in ethno-racial inequality at school and on the labour market and in international comparisons, with a focus on France and Germany. Her current research focuses on the life courses of migrants' descendants in Germany using mixed methods, and on ethnic boundary making strategies and reactions to discrimination. 